\title{
Redox regulation of mast cell histamine release in thioredoxin-1 (TRX) transgenic mice
}

Aoi Son ${ }^{1}$, Hajime Nakamura ${ }^{2}$, Norihiko Kondo ${ }^{1}$, Yoshiyuki Matsuo ${ }^{1}$, Wenrui Liu ${ }^{1}$, Shin-ichi Oka ${ }^{1}$, Yasuyuki Ishii ${ }^{3}$, Junji Yodoi ${ }^{1,2}$

${ }^{I}$ Department of Biological Responses, Institute for Virus Research, Kyoto University, 53 Shogoin Kawahara-cho, Sakyo-ku, Kyoto 606-8507, Japan; ${ }^{2}$ Department of Experimental Therapeutics, Translational Research Center, Kyoto University Hospital, 54 Shogoin Kawahara-cho, Sakyo-ku, Kyoto, 606-8507, Japan; ${ }^{3}$ Research Unit for Clinical Allergy, RIKEN Research Center for Allergy and Immunology, 1-7-22 Suehiro-cho, Tsurumi-ku, Yokohama, 230-0045, Japan

Thioredoxin-1 (TRX) is a stress-inducible redox-regulatory protein with antioxidative and anti-inflammatory effects. Here we show that the release of histamine from mast cells elicited by cross-linking of high-affinity receptor for IgE (FceRI) was significantly suppressed in TRX transgenic (TRX-tg) mice compared to wild type (WT) mice. Intracellular reactive oxygen species (ROS) of mast cells stimulated by IgE and antigen was also reduced in TRX-tg mice compared to WT mice. Whereas there was no difference in the production of cytokines (IL-6 and TNF- $\alpha$ ) from mast cells in response to 2,4-dinitrophenylated bovine serum albumin (DNP-BSA) stimulation in TRX-tg and WT mice. Immunological status of TRX-tg mice inclined to T helper (Th) 2 dominant in primary immune response, although there was no difference in the population of dendritic cells (DCs) and regulatory T cells. We conclude that the histamine release from mast cells in TRX-tg mice is suppressed by inhibition of ROS generation. As ROS are involved in mast cell activation and facilitate mediator release, TRX may be a key signaling molecule regulating the early events in the IgE signaling in mast cells and the allergic inflammation.

Cell Research (2006) 16:230-239. doi:10.1038/sj.cr.7310031; published online 16 February 2006

Keywords: thioredoxin, redox, mast cell, histamine release, allergy

\section{Introduction}

Thioredoxin-1 (TRX) is a small $(12 \mathrm{kDa})$ multifunctional protein with redox-active dithiol/disulfide in the active site; -Cys-Gly-Pro-Cys- $[1,2]$. TRX was originally discovered in Escherichia coli as an electron donor for ribonucleotide reductase. We cloned human TRX as an adult $\mathrm{T}$ cell leukemia-derived factor (ADF) produced by human $\mathrm{T}$ cell leukemia virus type-I-transformed $\mathrm{T}$ cells [3]. Previous studies have shown that TRX is induced by various stresses including viral infection, exposure to UV light, x-ray irradiation, and hydrogen peroxide [4]. Indeed,

Correspondence: Junji Yodoi

Tel: +81-75-751-4024; Fax: +81-75-761-5766;

E-mail: yodoi@virus.kyoto-u.ac.jp truncated TRX (Trx80), which is the N-terminal partial (180 or 1-84) polypeptide of TRX, is identical to eosinophil cytotoxicity-enhancing factor (ECEF) which activates eosinophils and monocytes $[5,6]$. It is also reported that Trx80 affects human monocytes and directs the immune system to Th1 responses via IL-12 production [7].

TRX transgenic (TRX-tg) mice that carry the human TRX transgene under the control of $\beta$-actin promoter and overexpress human TRX throughout the body are more resistant to oxidative stress-associated disorders including focal cerebral ischemia [8], influenza virus-induced pneumonia [9], cytokine- or bleomycin-induced acute lung injury [10], and hepatitis caused by lipopolysaccharide (LPS) [11] and survive longer than wild type C57BL/6 mice [12].

Allergic mechanisms are complex, but they are resolved 
into three main stages. First, initial exposure to allergen leads to activation of allergen-specific Th2 cells and IgE synthesis. Subsequent exposures to allergen cause degranulation by IgE-sensitized mast cells. Cytokines or chemokines released by mast cells contribute to the late allergic responses. At the initial stage, dendritic cells (DCs) play an important role in Th cell polarization, and IL-12 secreted by DCs leads to the differentiation of Th cells into Th1 cells. Th2 responses that are characteristic of allergic reaction can be regulated by $\mathrm{CD} 4{ }^{+} \mathrm{CD} 25^{+}$regulatory $\mathrm{T}$ cells [13]. Mast cells and basophils play pivotal roles in the early allergic responses. The cross-linking of the highaffinity receptor for $\mathrm{IgE}$ (FceRI) on these cells activates intracellular signaling pathways that lead to degranulation and release of histamine and other mediators which cause allergic inflammation [14].

Oxidative stresses have been involved in the pathogenesis of allergic disease and inflammation. A recent report demonstrated that upon antigen-specific interaction of DCs with $\mathrm{T}$ cells, the intracellular oxidative state of DCs was elevated [15]. This increase in reactive oxygen species (ROS) was detected in the process of antigen presentation and not during activation of DCs. Furthermore, hydrogen peroxide also activates DCs, indicating that the generation of oxidants is important for DC function [16, 17]. During antigen presentation, DCs uptake cystine and release cysteine and TRX. TRX accumulates intracellulaly in DCs upon maturation and is secreted after interaction with antigen-specific T cells [18]. ROS are also induced in FceRI-stimulated mast cells and these oxidants produced endogenously play an important role in regulation of various mast cell responses, including degranulation and cytokine production [19].

It was reported that TRX prevents allergic reaction especially in the inflammatory phase, but its mechanism remains to be elucidated. In this study, we investigated the effect of TRX on the sequence of allergic responses. First, we stimulated mast cells from WT and TRX-tg mice with cross-linking of FceRI, and measured histamine release and supernatant cytokines. Second, we compared serum levels of immunoglobulins in WT and TRX-tg mice. Finally, we analyzed the percentage of the immune cells such as DCs or $\mathrm{CD} 4{ }^{+} \mathrm{CD} 25^{+} \mathrm{T}$ cells in WT mice and TRX-tg mice.

\section{Materials and Methods}

\section{Mice}

8 to 12 -week-old C57BL/6 mice (WT mice) were purchased from Japan SLC (Shizuoka, Japan). TRX-tg mice were established as described previously [8].

\section{Generation of mast cells}

Bone marrow derived mast cells were obtained according to the method described previously [20]. Briefly, bone marrow cells were flushed from the femurs of WT and TRX-tg mice, filtered through $40 \mu \mathrm{m}$ cell strainer (BD Falcon, Bedford, MA), and cultured in RPMI 1640 medium supplemented with 15\% FCS, $50 \mu \mathrm{M}$ 2-mercaptoethanol and $180 \mathrm{pM}$ mouse recombinant IL-3 purchased from PeproTech. Passages were made every week. More than $95 \%$ of the cells were identified as immature mast cells 4 weeks after the initiation of the culture.

\section{Histamine release assay}

Mast cells were sensitized overnight with anti-2,4-dinitrophenylated (DNP) $\operatorname{IgE}(1 \mu \mathrm{g} / \mathrm{ml})$ and stimulated with Ag, DNP- bovine serum albumin (BSA) $(300 \mathrm{ng} / \mathrm{ml})$, for $20 \mathrm{~min}$. Then cells were placed on ice to stop reaction. Supernatant was collected and histamine released into medium was measured by HPLC.

\section{Flow cytometric analysis}

Cells were incubated with antibodies for $20 \mathrm{~min}$ at $4^{\circ} \mathrm{C}$. The following eBioscience mouse antibodies were used: PE-conjugated anti-FceRI $\alpha$ (MAR-1), PE-conjugated anti-CD117 (2B8), PE-conjugated anti-CD11c (N418), PE-conjugated anti-CD80 (16-10A1), PE-conjugated anti-CD86 (GL1) FITC-conjugated MHC class II (M5/114.15.2). FITC-conjugated anti-CD4 mAb (H129.19) PE-conjugated anti-CD25 mAb (3C7) were purchased from BD Phermingen. Flow cytometric analysis was performed using a FACSCalibur (BD Biosciences, Mountain View, CA) with Flowjo software (Tree Star, Ashland, OR).

\section{Cytokine assay}

To determine the production of cytokines, mast cells were sensitized overnight with anti-DNP IgE and stimulated with Ag, DNP-BSA for $24 \mathrm{~h}$, and supernatants were collected and assayed for IL-6, TNF- $\alpha$ and IL-12 by ELISA using Duo-set ELISA kits (R\&D systems, Minneapolis, MN).

\section{Fluorescent detection of intracellular ROS by flow cytom- etry}

Intracellular ROS was measured according to the methods described previously [21]. Briefly, BMMC were sensitized with antiDNP IgE overnight, and stimulated with DNP-BSA for $30 \mathrm{~min}$. Then BMMC were incubated with $5 \mu \mathrm{M}$ 2',7'-dichlorofluorescein diacetate (DCFH-DA) for $30 \mathrm{~min}$. Intracellular ROS was measured using the cell-permeable, oxidation-sensitive dye DCFH-DA.

\section{Epicutaneous sensitization}

Epicutaneous sensitization of mice was performed as described previously [22]. Briefly, mice were anesthetized with ketalar and flunitrazepam and shaved on the back with depilatory (Kanebo, Tokyo, Japan). $100 \mu \mathrm{g}$ of DNP-OVA (LSL) in $100 \mathrm{ml}$ of normal saline was placed on $1 \mathrm{~cm}^{2}$ sterile gauze. Patches were fixed and secured to skin with transparent bio-occlusive dressings (3 M, Tokyo, Japan). The patch was placed for 1 week and then removed. Each course of immunization was repeated 3 times at 2 weeks intervals. On day 0 , 35 , and 50 , mice were bled and sera were prepared.

\section{Intraperitoneal (i.p.) sensitization}

Mice were sensitized with an i.p. injection of DNP-OVA (100 $\mathrm{mg}$ ) in aluminum hydroxide gel and normal saline. On day 14 , mice were bled and sera were prepared. 
Determination of serum levels of $\operatorname{IgE}$ and $\operatorname{IgG}$ subclasses

Total IgE in sera was determined by means of ELISA kit (Morinaga, Yokohama, Japan). IgG subclasses in sera were determined with ELISA. Briefly, 96-well microplates (Nunc, Wiesbaden-Schiertein, Germany) were coated with DNP-BSA in $50 \mathrm{mM}$ carbonate buffer ( $\mathrm{pH}$ 9.0) and incubated overnight at $4^{\circ} \mathrm{C}$. After blocking, diluted samples were added and incubated for $3 \mathrm{~h}$ at RT. DNP-specific IgG1 or IgG2a were detected using horseradish peroxidase (HRP)-labeled anti-mouse IgG1 or IgG2a (Zymed, San Francisco, CA), respectively. The colorimetric reaction was developed by TNB+ substrate-chromogen (DAKO, Carpinteria, CA). The optical density of each well was determined by using a microplate reader.

\section{Splenic DCs preparation}

Spleens were digested with collagenase D $(1 \mathrm{mg} / \mathrm{ml})$ in PBS for $40 \mathrm{~min}$ at $37^{\circ} \mathrm{C}$. Low-density cells were separated with BSA gradient centrifugation (Sigma, St. Louis, MO). CD11 $\mathrm{c}^{+}$cells were collected by using MACS beades (Miltenyi Biotec, Bergisch Gladbach, Germany). DCs were stimulated with $100 \mathrm{ng} / \mathrm{ml}$ LPS (Sigma, St. Louis, $\mathrm{MO})$ for $24 \mathrm{~h}$.

\section{$R T-P C R$}

Total RNA was isolated from whole splenocytes by using RNeasy Mini kit (QIAGEN, Hilden, Germany). cDNA was amplified by SuperScript III First-strand synthesis system for RT-PCR (Invitrogen, Carlsbad, CA). The RT products were amplified by means of PCR for 30 cycles. The primer set for IL- 4 and IFN- $\gamma$ were purchased from CLP (San Diego, CA).

\section{Statistical analysis}

For statistical analysis, we performed $t$ test. Results are expressed as mean $\pm \mathrm{SD}$.

\section{Results}

Lower release of histamine from mast cells in TRX-tg mice than WT mice

Culturing bone marrow cells from WT and TRX-tg mice in IL-3-containing medium for 4 weeks leads to the generation of $>95 \%$ pure population of mast cells. These mast cells express similar levels of FceRI and c-kit (CD117) on their cell surfaces (Figure 1A). The secretion of histamine was significantly suppressed in FceRI-stimulated mast cells from TRX-tg mice more than that from WT mice (Figure 1B). We examined intracellular ROS which have been implicated in degranulation in mast cells. Intracellular ROS was reduced in the mast cells of TRX-tg mice, compared to WT mice (Figure 1C). These results indicate that TRX suppresses the degranulation of mast cells through inhibition of ROS accumulation. Late-phase reaction of immediate hypersensitivity appears to be partly dependent on the production of cytokines such as IL- 6 and TNF- $\alpha$ from FceRI-stimulated mast cells. Mast cells from TRX-tg mice secreted higher IL- 6 at low concentration of DNP-BSA than that from WT mice, but the secretion of TNF- $\alpha$ was not significantly different from WT mice (Figure 1D).
Higher serum levels of Th2-mediated immunoglobulins in TRX-tg mice than in WT mice at primary immune response

We analyzed serum levels of total $\operatorname{IgE}$ in epicutaneous sensitization which leads to Th2 responses. On day 35 , the levels of total IgE were increased in TRX-tg mice compared with those in WT mice, but on day 50, the levels of those immunoglobulins were not different between WT and TRXtg mice (Figure 2A). These results suggested that levels of the Th2-mediated immunoglobulins were increased in TRX-tg mice during earlier immune responses. For analyzing the primary immune responses, we next examined serum levels of total IgE and antigen specific IgG subclasses in i.p. sensitization. Mice were injected DNP-OVA in alum through i.p., and 2 weeks later were bled. Sera were prepared for determination of immunoglobulin levels. The levels of total IgE and DNP-specific IgG1 were increased in TRX-tg mice compared with those in WT mice. In contrast, the level of IgG2a in the sera of TRX-tg mice was lower than that in WT mice (Figure 2B). The expression of Th1 or Th2 response-related genes after immunization in spleen was examined by means of RT-PCR. IL-4 was not detected, but IFN- $\gamma$ expression was decreased in the spleen of TRX-tg mice (Figure 2C). These results suggest that immunological status of TRX-tg mice was inclined to $\mathrm{Th} 2$ dominant in primary immune response, however, the Th2 cell development of challenged TRX-tg mice was not increased compared to WT mice.

No difference in the population of DCs and $C D 4^{+} C D 25^{+}$ regulatory T cells in TRX-tg and WT mice

To characterize the phenotype of immune regulatory cells, especially DCs and $\mathrm{CD} 4^{+} \mathrm{CD} 25^{+}$regulatory $\mathrm{T}$ cells, in TRX-tg mice, single cell suspension obtained from spleen was stained with several immune cell markers and analyzed by flow cytometry. There were no differences in DC populations between WT and TRX-tg mice (Figure 3A). Moreover, we stimulated DCs with LPS and analyzed some surface molecules which represented DC maturation. DC maturation of those mice did not differ (Figure 3B). There was also no difference in the $\mathrm{CD} 4^{+} \mathrm{CD} 25^{+}$cell population of those mice (Figure 4).

\section{Discussion}

Mast cells are derived from $\mathrm{CD} 34^{+}$haematopoietic progenitor cells [14]. We generated mast cells from bone marrow cells of WT and TRX-tg mice under IL-3-containing medium for 4 weeks. The expression of FceRI and c-kit (CD117) on mast cells and the number of cells were not different between WT and TRX-tg mice (Figure 1A). These results suggest that TRX overexpression does not 
A

WT

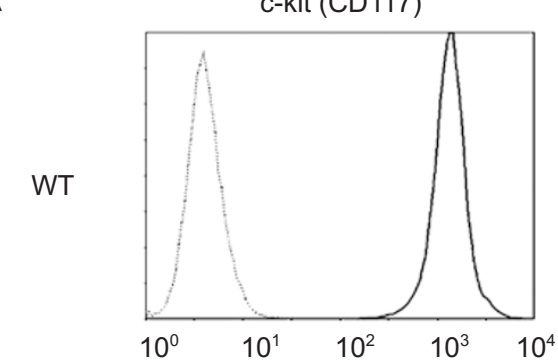

TRX-tg

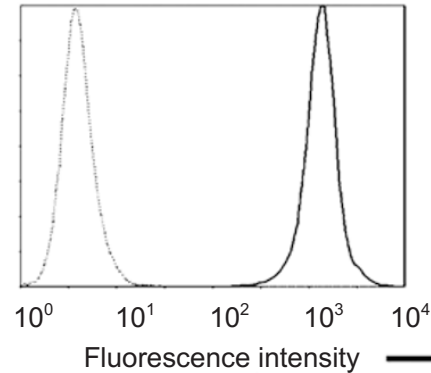

B

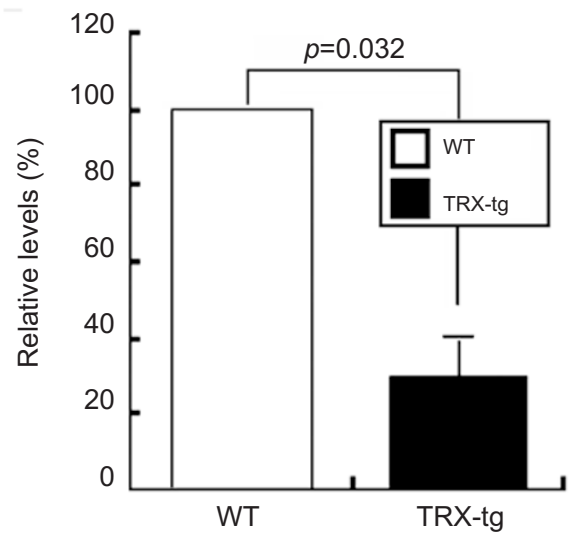

$\mathrm{D}$

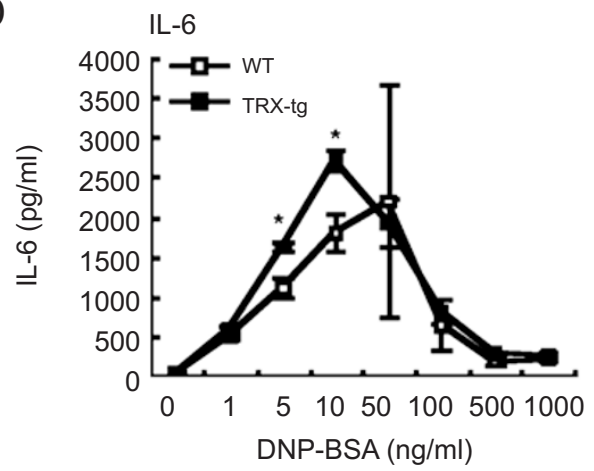

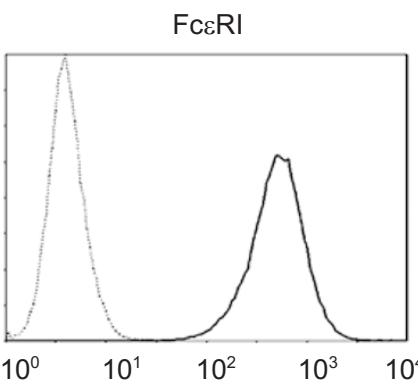

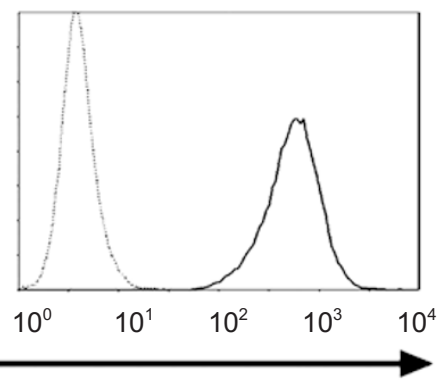

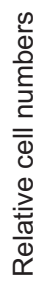
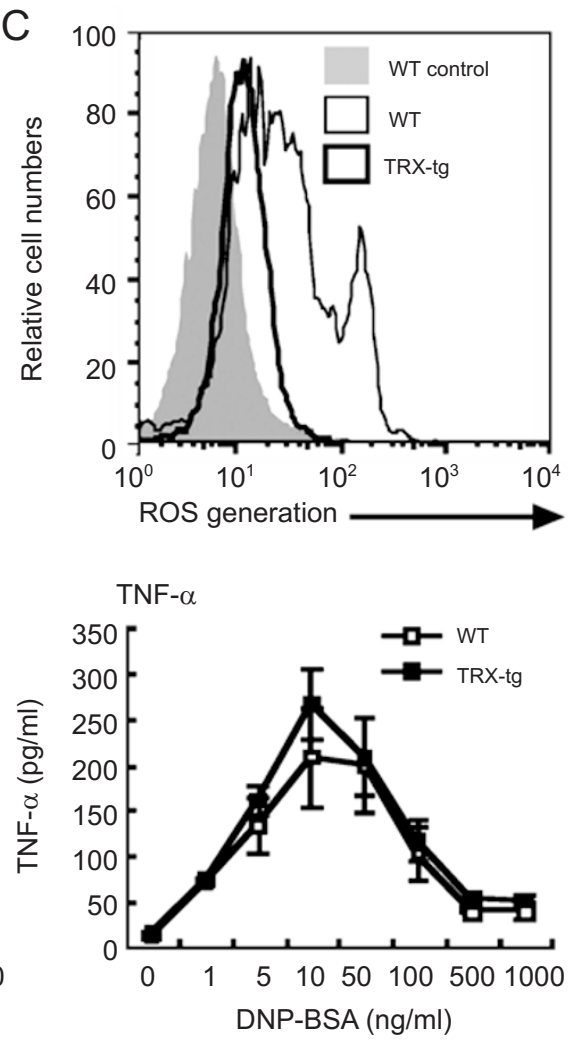

Figure 1 Characterization of mast cells from WT and TRX-tg mice. (A) Expression of FceRI and c-kit (CD117) on the surface of mast cells from WT and TRX-tg mice. Mast cells derived from bone marrow cells were cultured with IL-3 for 4 weeks. Flow cytometric analysis of these cells were performed. (B) Histamine release from WT and TRX-tg mast cells upon Fc\&RI cross-linking. Mast cells were sensitized overnight with anti-DNP IgE and stimulated with Ag, DNP-BSA for $20 \mathrm{~min}$. Histamine released into medium was measured by HPLC. ${ }^{*} p<0.05$. (C) Intracellular ROS in mast cells measured by flow cytometer. BMMC were sensitized with anti-DNP IgE overnight, and stimulated with DNP-BSA for $30 \mathrm{~min}$. We used untreated mast cells from WT mice as control. (D) Production of IL-6 and TNF- $\alpha$ from FceRI-stimulated WT and TRX-tg mast cells. Mast cells were sensitized overnight with anti-DNP IgE and stimulated with $\mathrm{Ag}$ for $24 \mathrm{~h}$. Cytokines secreted into medium were measured by ELISA. *, significantly different from WT at same concentration of DNP-BSA $(p<0.05)$ 
A

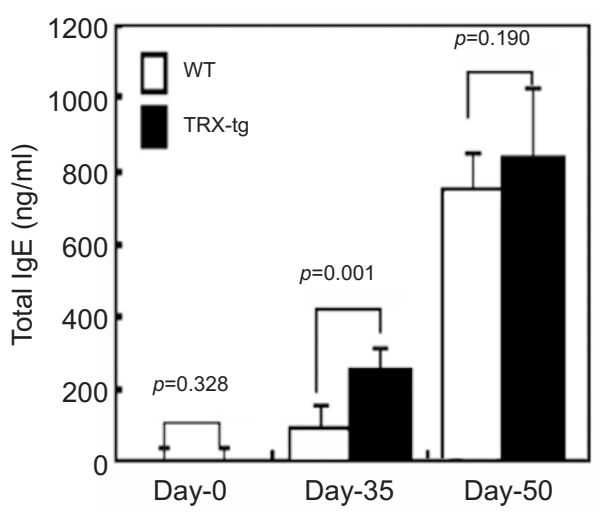

B

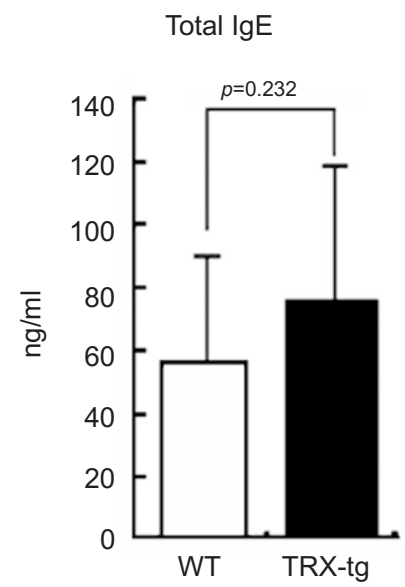

C

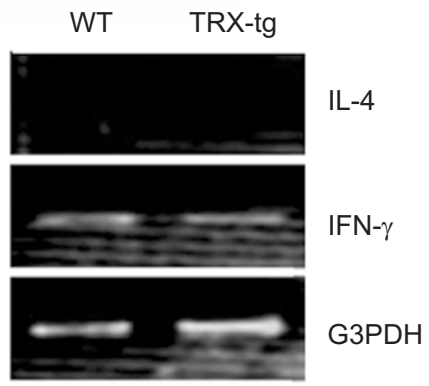

Figure 2 The immunological status of sensitized TRX-tg mice. Total IgE and antigen-specific antibody response in WT and TRX-tg mice sensitized with DNP-OVA by epicutaneous (A) or i.p. (B) sensitization. (C) The expression of Th1-, or Th2-related genes in the spleen. RNA was purified from spleen $3 \mathrm{~d}$ after i.p. injection of Ag and alum and subjected to RT-PCR.

change the population and differentiation of bone marrow derived mast cells.

We found that the histamine release of mast cells generated from TRX-tg mice was significantly decreased compared with that from WT mice (Figure 1B). The crosslinking of FceRI with antigen results in activation of Lyn and Syk [23]. Lyn and Syk phosphorylate a number of targets such as phospholipase C (PLC) $\gamma$ and Btk [24, 25]. PLC $\gamma$ activation causes inositol triphosphate (IP3) and diacylglycelol, which play an important role in $\mathrm{Ca}^{2+}$ influx and in activation of protein kinase $\mathrm{C}$ (PKC), respectively. Optimal degranulation requires both modestly increased intracellular $\mathrm{Ca}^{2+}$ concentrations and activation of PKC isoforms [26]. ROS, functionally linked to mast cell activation, facilitate mediator release and activate PLC $\gamma$, PKC and $\mathrm{Ca}^{2+}$ influx. Since ROS reduction by TRX is mediated through multiple mechanisms [27], one would speculate that PLC $\gamma, \mathrm{PKC}$, and $\mathrm{Ca}^{2+}$ influx activated by ROS will be suppressed in TRX-tg mice, as depicted in Figure 5 and supported by our data of reduction of ROS in mast cells from TRX-tg mice (Figure 1C). These results suggest that the histamine release from TRX-tg mast cells was impaired through reduction of ROS.

Degranulation and cytokine secretion are separable independent process; i.e., early- and late- phase reaction triggered by the cross-linking of FceRI respectively. The signaling pathways leading to the secretion of cytokines are distinct from that leading to the release of histamine. FceRI ligation results in the activation of mitogen-activated protein kinase (MAPK) pathways that include c-Jun N-terminal kinase (JNK) and p38 MAPK. JNK and p38 MAPK activate transcription factors that regulate the expression of cytokine genes such as IL- 6 and TNF- $\alpha$ [28-31]. It is known that ROS activates the signaling pathways to NF$\kappa \mathrm{B}$, which are suppressed by TRX overexpression through scavenging of ROS in cytosol. On the other hand, in the 
A

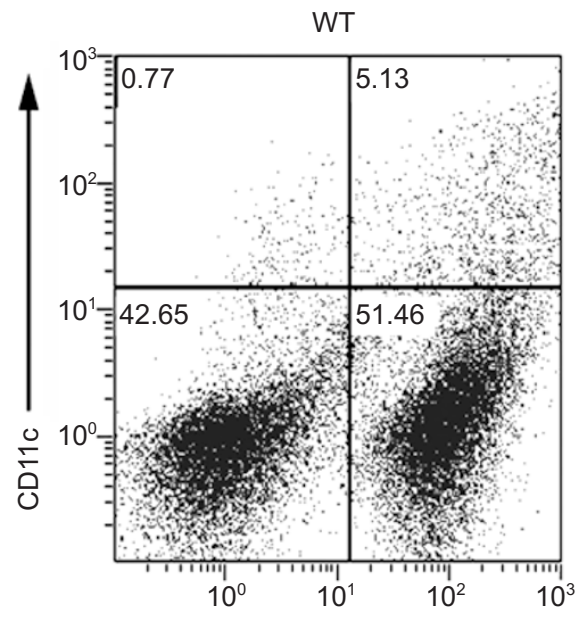

$\mathrm{MHC}$ class II

B
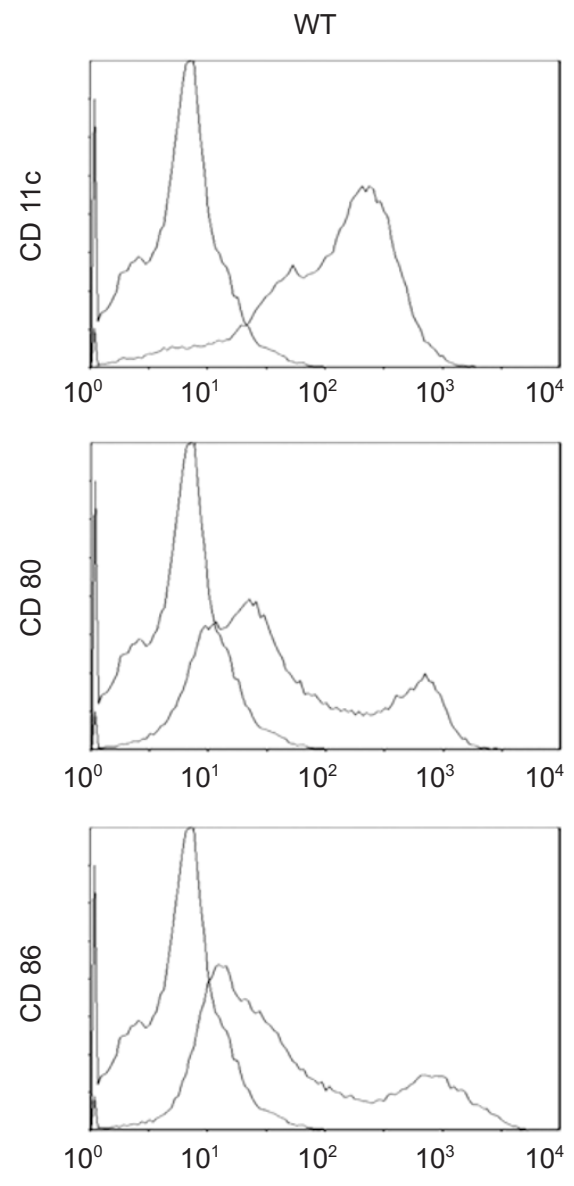

TRX-tg

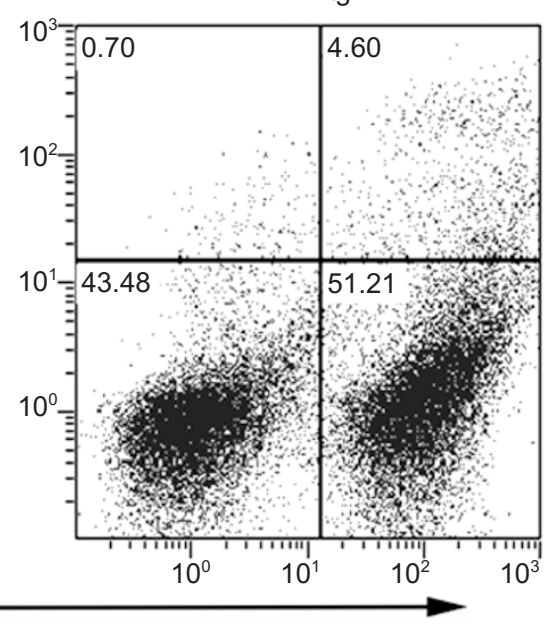

TRX-tg
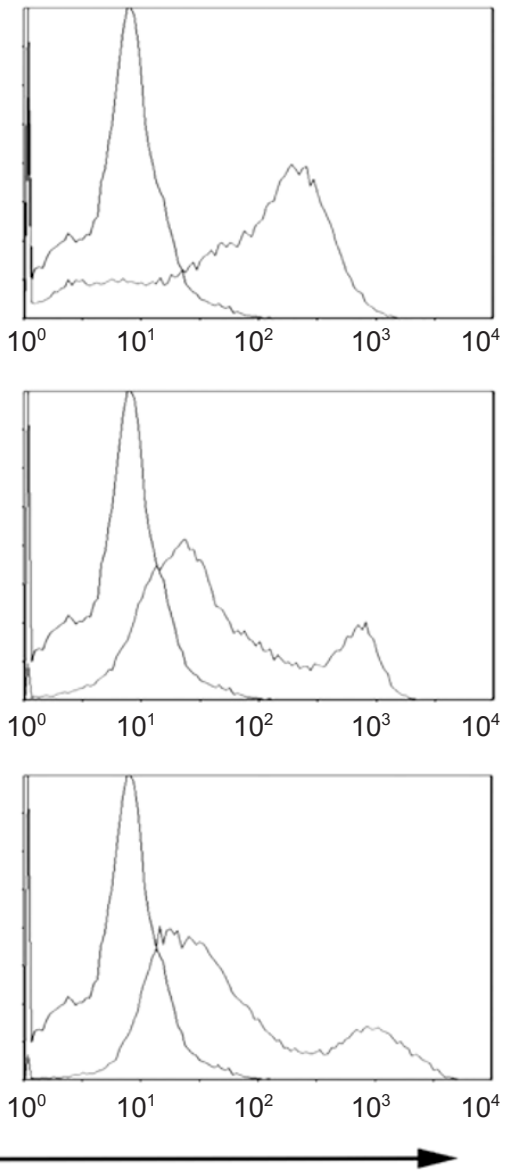

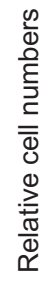

Figure 3 Characteization of DCs from WT and TRX-tg mice. (A) Splenocytes were analyzed for CD11c and MHC class II double positive cell profiles. (B) The surface expression of costimulatory molecules on LPS-stimulated DCs from WT and TRX-tg mice.

nucleus, TRX enhances the DNA-binding activity of NF$\kappa \mathrm{B}$, which is essential for transcription of target genes including IL-6 and TNF- $\alpha$ [27]. Our present date showed that TRX did not have a remarkable effect on cytokine 
WT

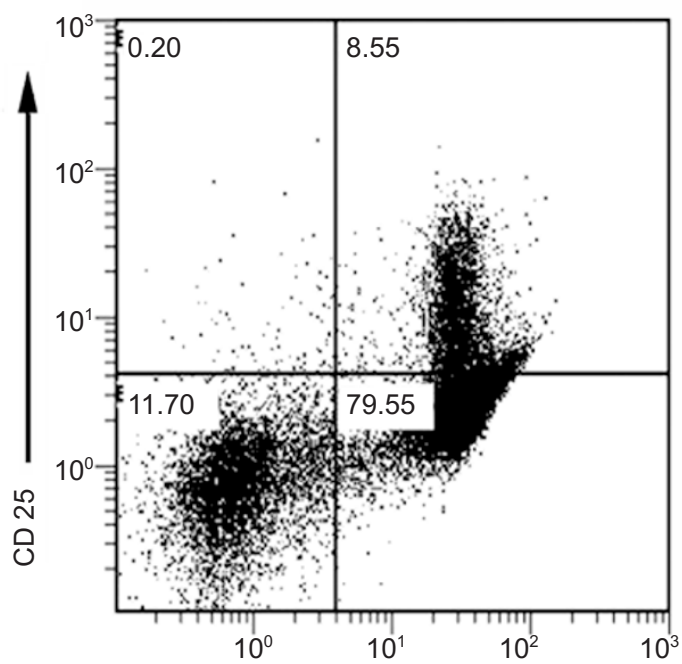

TRX-tg

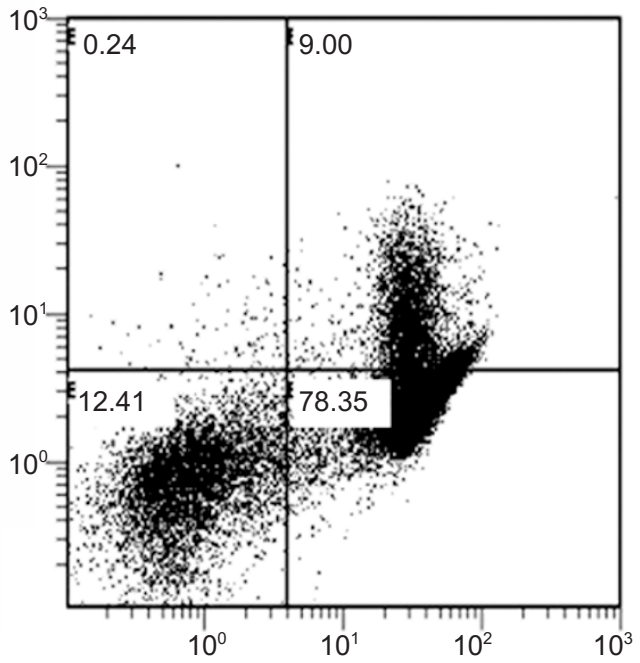

CD 4

Figure 4 The population of CD4 $4^{+} \mathrm{CD} 25^{+} \mathrm{T}$ cells from WT and TRX-tg mice. Splenocytes were analyzed for CD4 and CD25 double positive cell profiles.

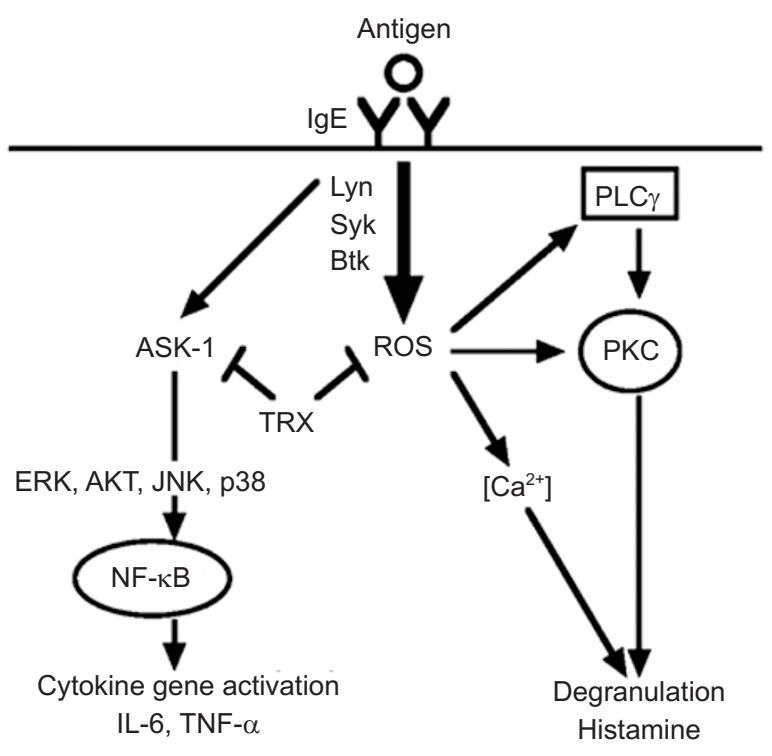

Figure 5 Hypothetical schema of TRX regulation in FceRI-induced activation pathway. The cross-linking of FceRI with the antigen results in activation of Lyn, Syk, Btk, and PLC $\gamma$. PLC $\gamma$ activation plays an important role in $\mathrm{Ca}^{2+}$ influx and in activation of PKC. ROS which induced in FceRI-stimulated mast cells are functionally linked to mast cell activation and activate PLC $\gamma$, PKC and $\mathrm{Ca}^{2+}$ influx. TRX may prevent histamine release from mast cells by scavenging ROS.

secretions in mast cells, which may be due to the TRX inhibitory effect on cytosolic NF-kB, thereby leading to less nuclear NF- $\mathrm{BB}$ available for transcription activity for cytokines (Figure 1D).

We demonstrate that TRX prevents histamine release from mast cells, which is an essential reaction of allergic diseases. We reported that serum TRX levels increased in patients with asthma, especially in the phase of asthma attack [32]. Oxidative stress and oxidants have been implicated in the pathogenesis of asthma, and increased release of ROS. Activated eosinophils in asthma secrete ROS and granular basic proteins that damage the bronchial epithelium cause vasodilation and airway hyperresponsiveness $[33,34]$. Since asthma is characterized by prominent production of ROS from inflammatory cells, it is suggested that the secretion of TRX into serum may be a kind of host-defense reaction against ROS. In addition, TRX suppresses eosinophilic inflammation through eosinophil infiltration in the airway during asthma attack, and minimize the allergic inflammation. It is also reported that TRX regulates eosinophil migration through redox regulation by a dithiol reductase activity [35]. Thus, oxidative stresses, including that caused by ROS, may play a critical role in the pathogenesis of asthma. Recently we have shown that TRX inhibits OVA-induced airway hyperresponsiveness and inflammation in a mouse asthma model [36]. In the antigen-induced airway inflammation of asthma, Th2 cytokines (e.g., IL-4, IL-5 and IL-13) enhance the development of IgE production and eosinophilic airway infiltration. DCs play a key role in capturing, processing, transporting, and 
presenting antigens to T cells. DCs initiate primary T cell responses by antigen-presentation, consequently promote Th1-, Th2-, or regulatory T cell responses. Various DCderived molecules induce Th cell polarization have been identified. For example, Th1-polarizing cytokines are IL-12 and IFN- $\gamma$, whereas Th2-polarizing cytokines are IL-10 and TGF- $\beta$. Among them, IL-12 is an important cytokine that promotes Th1-response. It was reported that Apoptosis signal-regulating kinase 1 (ASK1), a mitogen-activated protein (MAP) kinase kinase kinase which activates the JNK and p38 MAP kinase pathway, is involved in immune responses dependent on TLR4. Production of IL-12 in ASK1-deficient DCs was reduced relative to that in control DCs [37]. TRX interacts with ASK1 and is a physiological inhibitor of ASK1. Although no differences in population or maturation of DCs between WT and TRX-tg mice are observed (Figure 3 ), it is still likely that IL-12 production in TRX-tg mice would be reduced via suppressing ASK1 activity, and this reduced IL-12 production induces Th2-response in TRX-tg mice. It was also reported that ASK-1 activates activator protein-1 (AP-1) through JNK/p38 MAPK signaling pathway in human bronchial asthma [38].

We showed that TRX-tg mice were inclined to develop Th2 reaction during primary immune response (Figure 2 ), and the percentage of $\mathrm{CD} 4{ }^{+} \mathrm{CD} 25^{+}$regulatory $\mathrm{T}$ cells in TRX-tg mice was not different from that in WT mice (Figure 4). It is suggested that the suppression of allergic reaction and inflammation in TRX-tg mice may not depend on Th1/Th2 polarization or immune suppressive cells. On the other hand, it was reported that TRX-tg mice are more resistant to diesel exhaust particles (DEP)-induced acute lung damage than WT mice. DEP causes acute injury with airway neutrophilic inflammation and the generation of ROS. TRX inhibits DEP-induced acute lung damage by scavenging ROS and by regulating Akt-mediated antiapoptotic signaling [39]. Exposure to DEP with antigen enhances airway inflammation, airway hyperresponsiveness, the production of antigen-specific IgE and IgG1, and the local expression of cytokines [40]. Further study will clarify the effect of TRX on the airway hyperresponsiveness and eosinophilic inflammation caused by DEP.

The suppressive effect of TRX on inflammatory or allergic diseases may be possibly not only due to scavenging ROS but also another modulating system. For example, macrophage migration inhibiting factor (MIF) plays a crucial role in allergic inflammation [41]. Glycosylation inhibitory factor (GIF) is cystinylated molecule of MIF [42] and was originally identified as an inhibitory factor of Ig E antibody response [43]. MIF has the conserved sequence motif of the TRX family consisting of -C-X-X-C- [44] and the expression level of MIF is reciprocally regulated by TRX [45]. Interestingly, MIF is down-regulated in TRX- tg mice (Tamaki et al., unpublished data). Also we are confirming our preliminary date of the direct interaction of TRX and MIF/GIF (in preparation). Future work will aim to clarify that the role of MIF/GIF in the redox regulation of allergic inflammation is regulated by TRX.

In conclusion, the present study shows that the release of histamine from mast cells was suppressed in TRX-tg mice and intracellular ROS in mast cells from TRX-tg mice was reduced. Our results suggest that TRX may have a protective effect against allergic inflammation and diseases.

\section{Acknowledgements}

We thank Dr Y Yoshida for excellent technical assistance and Drs H Masutani, M Tanito and A Teratani for scientific discussion. This study was supported by a grant-in-aid for scientific research from the Ministry of Education, Culture, Sports, Science, and Technology of Japan (contract grant No. 15209015); and a grant-in-aid for the Research and Development Program for New Bio-Industry Initiatives, Bio-oriented Technology Research Advancement Institution, Japan.

\section{References}

1 Holmgren A. Thioredoxin. Annu Rev Biochem 1985; 54:23771.

2 Holmgren A. Thioredoxin and glutaredoxin systems. J Biol Chem 1989; 264:13963-6.

3 Tagaya Y, Maeda Y, Mitsui A, et al. ATL-derived factor (ADF), an IL-2 receptor/Tac inducer homologous to thioredoxin: possible involvement of dithiol reduction in the IL-2 receptor induction. EMBO J 1989; 8:757-64.

4 Nakamura H, Nakamura K, Yodoi J. Redox regulation of cellular activation. Annu Rev Immunol 1997; 15:351-69.

5 Silberstein DS, McDonough S, Minkoff MS, Balcewicz-Sablinska MK. Human eosinophil cytotoxicity-enhancing factor: Eosinophil-stimulating and dithol reductase activities of biosynthetic (recombinant) species with $\mathrm{COOH}$-terminal deletions. J Biol Chem 1993; 268:9138-42.

6 Pekkari K, Gurunath R, Arner ESJ, Holmgren A. Ttuncated thioredoxin is a mitogenic cytokine for resting human peripheral blood mononuclear cells and is present in human plasma. J Biol Chem 2000; 275:37474-80.

7 Pekkari K, Avila-Carino J, Bengtsson A, et al. Truncated thioredoxin (Trx80) induces production of interleukin-12 and enhances CD14 expression in human monocytes. Blood 2001; 97:318490.

8 Takagi Y, Mitsui A, Nishiyama A, et al. Over-expression of thioredoxin in transgenic mice attenuates focal ischemic brain damage. Pro Natl Acad Sci U S A 1999; 96:4131-6.

9 Nakamura H, Tamura S, Watanabe I, Iwasaki T, Yodoi J. Enhanced resistancy of thioredoxin-transgenic mice against influenza virus-induced pneumonia. Immunol Lett 2002; 82:16570 .

10 Hoshino T, Nakamura H, Okamoto M, et al. Redox-active protein 
thioredoxin prevents proinflammatory cytokine- or bleomycininduced lung injury. Am J Respir Crit Care Med 2003; 168:107583.

11 Okuyama H, Nakamura H, Shimahara Y, et al. Overexpression of thioredoxin prevents acute hepatitis caused by thioacetamide or lipopolysaccharide in mice. Hepatology 2003; 37:1015-25.

12 Mitsui A, Hamuro J, Nakamura H, et al. Overexpression of human thioredoxin in transgenic mice controls oxidative stress and life span. Antioxid Redox Signal 2002; 4:693-6.

13 Hawrylowicz CM, O'Garra A. Potential role of interleukin10 -secreting regulatory $\mathrm{T}$ cells in allergy and asthma. Nat Rev Immunol 2005; 5: 271-83.

14 Kawakami T, Galli SJ. Regulation of mast-cell and basophil function and survival by IgE. Nat Rev Immunol 2002; 2:773-86.

15 Matsue H, Edelbaum D, Shalhevet D, et al. Generation and function of reactive oxygen species in dendritic cells during antigen presentation. J Immunol 2003; 171:3010-8.

16 Verhasselt V, Goldman M, Willems F. Oxidative stress up-regulates IL-8 and TNF-a synthesis by human dendritc cells. Eur J Immunol 1998; 28:3886-90.

17 Rutault K, Alderman C, Chain BM, Katz DR. Reactive oxygen species activate human peripheral blood dendritic cells. Free Radic Med 1999; 26(1-2):232-8.

18 Angelini G, Gardella S, Ardy M, et al. Antigen-presenting dendritic cells provide the reducing extracellular microenvironment required for T lymphocyte activation. Proc Natl Acad Sci U S A 2002; 99:1491-6.

19 Suzuki Y, Yoshimura T, Inoue T, Niide O, Ra C. Role of oxidants in mast cell activation. Chem Immunol Allergy 2005; 87:3242.

20 Kawakami Y, Kitaura J, Satterthwaite AB, et al. Redundant and opposing functions of two tyrosine kinases, Btk and Lyn, in mast cell activation. J Immunol 2000; 165:1210-9.

21 Kondo N, Ishii Y, Kwon YW, et al. Redox-sensing release of human thioredoxin from $\mathrm{T}$ lymphocytes with negative feedback loops. J Immunol 2004; 172:442-8.

22 Spergel JM, Mizoguchi E, Brewer JP, et al. Epicutaneous sensitization with protein antigen induces localized allergic dermatitis and hyperresponsiveness to methacholine after single exposure to aerosolized antigen in mice. J Clin Invest 1998; 101:1614-22.

23 Penhallow RC, Class K, Sonoda H, Bolen JB, Rowley RB. Temporal activation of nontransmembrane protein-tyrosine kinases following mast cell Fc epsilon RI engagement. J Biol Chem 1995; 270:23362-5.

24 Kinet JP, Jouvin MH, Paolini R, Numerof R, Scharenberg A. IgE receptor (Fc epsilon RI) and signal transduction. Eur Respir J Suppl 1996; 22:116s-8s.

25 Hata D, Kawakami Y, Inagaki N, et al. Involvement of Bruton's tyrosine kinase in FceRI-dependent mast cell degranulation and cytokine production. J Exp Med 1998; 187:1235-47.

26 Ozawa K, Szallasi Z, Kazanietz MG, et al. $\mathrm{Ca}^{2+}$-dependent and $\mathrm{Ca}^{2+}$-independent isozymes of protein kinase $\mathrm{C}$ mediate exocytosis in antigen-stimulated rat basophilic RBL-2H3 cells; Reconstitution of secretory responses with $\mathrm{Ca}^{2+}$ and purified isozymes in washed permeabilized cells. J Biol Chem 1993; 268: $1749-56$.

27 Nishiyama A, Masutani H, Nakamura H, Nishinaka Y, Yodoi J. Redox regulation by thioredoxin and thioredoxin-binding proteins. IUBMB Life 2001; 52:29-33.

28 Ishizuka T, Chayama K, Takeda K, et al. Mitogen-activated protein kinase activation through $\mathrm{Fc}$ epsilon receptor I and stem cell factor receptor is differentially regulated by phosphatidylinositol 3-kinase and calcineurin in mouse bone marrow-derived mast cells. J Immunol 1999; 162:2087-94.

29 Hirasawa N, Santini F, Beaven MA. Activation of the mitogenactivated protein kinase/cytosolic phospholipase A2 pathway in a rat mast cell line; Indications of different pathways for release of arachidonic acid and secretory granules. J Immunol 1995; 154:5391-402.

30 Ishizuka T, Oshiba A, Sakata N, et al. Aggregation of FcepsilonRI on mast cells stimulates c-Jun amino-terminal kinase activity; A response inhibited by wortmannin. J Biol Chem 1996; 271:12762-6.

31 Csonga R, Perischl EE, Jaksche D, Novotny V, Baumruker T. Common and distinct signaling pathways mediate the induction of TNF-alpha and IL-5 in IgE plus antigen-atimulated mast cells. J Immunol 1998; 160:273-83.

32 Yamada Y, Nakamura H, Adachi T, et al. Elevated serum levels of thioredoxin in patients with acute exacerbation of asthma. Immunol Lett 2003; 86:199-205.

33 Bousquet J, Jeffery PK, Busse WW, Johnson M, Vignola AM. Asthma; From bronchoconstriction to airways inflammation and remodeling. Am J Respir Crit Care Med 2000; 161:1720-45.

34 Flood-Page PT, Menzies-Gow AN, Kay AB, Robinson DS. Eosinophil's role remains uncertain as anti-interleukin-5 only partially depletes numbers in asthmatic airway. Am J Respir Crit Care Med 2003; 167:199-204.

35 Hori K, Hirashima M, Ueno M, et al. Regulation of eosinophil migration by adult $\mathrm{T}$ cell leukemia-derived factor. $\mathrm{J}$ Immunol 1993; 151:5624-30.

36 Ichiki H, Hoshino T, Kinoshita T, et al. Thioredoxin suppresses airway hyperresponsiveness and airway inflammation in asthma. Biochem Biophys Res Commun 2005; 334:1141-8.

37 Matsuzawa A, Saegusa K, Noguchi T, et al. ROS-dependent activation of the TRAF6-ASK1-p38 pathway is selectively required for TLR4-mediated innate immunity. Nat Immunol 2005; 6:587-92.

38 Jibiki I, Hashimoto S, Maruoka S, et al. Apoptosis signalregulating kinase 1-mediated signaling pathway regulates nitric oxide-induced activator protein-1 activation in human bronchial epithelial cells. Am J Respir Crit Care Med 2003; 167:856-61.

39 Ahsan MK, Nakamura H, Tanito M, et al. Thioredoxin-1 suppresses lung injury and apoptosis induced by diesel exhaust particles (DEP) by scavenging reactive oxygen species and by inhibiting DEP-induced downregulation of Akt. Free Radic Biol Med 2005; 39:1549-59.

40 Miyabara Y, Takano H, Ichinose T, Lin HB, Sagai M. Diesel exhaust enhances allergic airway inflammation and hyperresponsiveness in mice. Am J Respir Crit Care Med 1998; 157:113844.

41 Mizue Y, Ghani S, Leng L, et al. Role for macrophage migration inhibitory factor in asthma. Pro Natl Acad Sci USA 2005; 102:14410-5.

42 Watarai H, Nozawa R, Tokunaga A, et al. Posttranslational modification of the glycosylation inhibiting factor (GIF) gene product generates bioactive GIF. Pro Natl Acad Sci U S A 2000; 97:13251-6. 
43 Ishizaka K. IgE-binding factors and regulation of the $\operatorname{IgE}$ antibody response. Annu Rev Immunol 1988; 6:513-34.

44 Kleemann R, Kapurniotu A, Frank RW, et al. Disulfide analysis reveals a role for macrophage migration inhibitory factor (MIF) as thiol-protein oxidoreductase. J Mol Biol 1998; 280:85-102.

45 Kondo N, Ishii Y, Son A, et al. Cysteine-dependent immune regulation by TRX and MIF/GIF family proteins. Immunol Lett 2004; 92:143-7. 